CURRENT CONCEPTS

\title{
Management of Varices and Variceal Hemorrhage in Cirrhosis
}

\author{
Guadalupe Garcia-Tsao, M.D., and Jaime Bosch, M.D.
}

V

ARICEAL HEMORRHAGE IS A LETHAL COMPLICATION OF CIRRHOSIS, PARticularly in patients in whom clinical decompensation (i.e., ascites, encephalopathy, a previous episode of hemorrhage, or jaundice) has already developed. Practice guidelines for the management of varices and variceal hemorrhage ${ }^{1}$ in cirrhosis are mostly based on evidence in the literature that has been summarized and prioritized at consensus conferences. ${ }^{2,3}$ There are three main areas of management: primary prophylaxis to prevent a first episode of variceal hemorrhage, treatment of the acute bleeding episode, and secondary prophylaxis (prevention of recurrent variceal hemorrhage).

\section{NATURAL HISTORY AND EPIDEMIOLOGY}

Gastroesophageal varices are present in almost half of patients with cirrhosis at the time of diagnosis, with the highest rate among patients with Child-Turcotte-Pugh (hereinafter called Child) class B or C disease (Table 1). ${ }^{4}$ Development and growth of gastroesophageal varices each occur at a rate of $7 \%$ per year. ${ }^{5,6}$ The 1-year rate of a first variceal hemorrhage is approximately $12 \%$ (5\% for small varices and $15 \%$ for large varices). ${ }^{7}$ Besides variceal size, red wale marks on varices and advanced liver disease (Child class B or C) identify patients at a high risk for variceal hemorrhage. ${ }^{8}$ The 1-year rate of recurrent variceal hemorrhage is approximately $60 \% .{ }^{9}$ The 6-week mortality with each episode of variceal hemorrhage is approximately 15 to $20 \%$, ranging from $0 \%$ among patients with Child class A disease to approximately $30 \%$ among patients with Child class $\mathrm{C}$ disease. ${ }^{10-12}$

PATHOPHYSIOLOGY AND PATHOPHYSIOLOGICAL BASES OF THERAPY

Gastroesophageal varices are a direct consequence of portal hypertension that, in cirrhosis, results from both increased resistance to portal flow and increased portal venous blood inflow. Increased resistance is both structural (distortion of liver vascular architecture by fibrosis and regenerative nodules) and dynamic (increased hepatic vascular tone due to endothelial dysfunction and decreased nitric oxide bioavailability). ${ }^{13}$

When the portal-pressure gradient (the difference between portal-vein pressure and hepatic-vein pressure) increases above a certain threshold, collaterals develop at sites of communication between the portal and systemic circulations. ${ }^{5}$ This process is modulated by angiogenic factors. ${ }^{14,15}$ Concomitantly with the formation of portosystemic collaterals, portal venous blood inflow increases as a result of splanchnic vasodilatation and increased cardiac output. ${ }^{16}$ Increased portal flow maintains
From the Section of Digestive Diseases, Yale University School of Medicine, New Haven, CT (G.G.-T.); and Hospital Clinic, Hepatic Hemodynamic Laboratory, Liver Unit, University of Barcelona, Barcelona (J.B.).

N Engl J Med 2010;362:823-32. Copyright @ 2010 Massachusetts Medical Society. 


\begin{tabular}{|c|c|c|c|}
\hline \multirow[t]{2}{*}{ Clinical and Biochemical Criteria } & \multicolumn{3}{|c|}{ Points: } \\
\hline & 1 & 2 & 3 \\
\hline Encephalopathy & None & Mild to moderate (grade 1 or 2 ) & Severe (grade 3 or 4 ) \\
\hline Ascites & None & Mild to moderate & Large or refractory to diuretics \\
\hline Bilirubin (mg/dl) & $<2$ & $2-3$ & $>3$ \\
\hline Albumin (g/dl) & $>3.5$ & $2.8-3.5$ & $<2.8$ \\
\hline \multicolumn{4}{|l|}{ Prothrombin time $\uparrow$} \\
\hline Seconds prolonged & $<4$ & $4-6$ & $>6$ \\
\hline International normalized ratio & $<1.7$ & $1.7-2.3$ & $>2.3$ \\
\hline
\end{tabular}

* In the Child-Turcotte-Pugh classification system, class A (5 to 6 points) indicates least severe liver disease, class B ( 7 to 9 points) indicates moderately severe liver disease, and class C (10 to 15 points) indicates most severe liver disease. To convert the values for bilirubin to micromoles per liter, multiply by 17.1.

$\uparrow$ Either seconds prolonged or the international normalized ratio is used.

and exacerbates portal hypertension. Gastroesophageal varices are the most important collaterals, because as pressure and flow increase through them, they grow and eventually rupture (Fig. 1).

Available therapies for varices and variceal hemorrhage can be classified according to whether they act on the physiological mechanisms of portal hypertension.

\section{THERAPIES THAT REDUCE PORTAL PRESSURE}

Splanchnic vasoconstrictors such as vasopressin and somatostatin (and their analogues, octreotide and vapreotide) are administered parenterally and are therefore restricted to use in an acute care setting. Nonselective beta-adrenergic blockers affect portal flow by means of both $\beta_{1}$-blockade (reduction of cardiac output) and $\beta_{2}$-blockade (splanchnic vasoconstriction). ${ }^{17}$ Therefore, nonselective beta-blockers such as propranolol or nadolol are better than selective beta-blockers because of broader mechanisms of action. They are administered orally and are used in the long-term treatment of portal hypertension.

Drugs that increase the delivery of nitric oxide to the intrahepatic circulation, such as nitrates and simvastatin, and drugs that block adrenergic activity (e.g., prazosin and clonidine) or that block angiotensin (e.g., captopril, losartan, and irbesar$\tan )$ act by inducing intrahepatic vasodilatation. ${ }^{17}$ Unfortunately, venodilators may also cause systemic vasodilatation, with aggravation of sodium retention and renal vasoconstriction. ${ }^{18,19}$ An exception may be simvastatin, which acts on the dys- functional intrahepatic endothelium without an effect on the systemic circulation. ${ }^{20,21}$

The combination of vasodilators and splanchnic vasoconstrictors, such as the combination of nonselective beta-blockers plus nitrates or carvedilol (a nonselective beta-blocker with an added vasodilatory effect through anti- $\alpha_{1}$-adrenergic activity), has an additive portal pressure-reducing effect but can also decrease arterial pressure. ${ }^{22}$

Notably, none of the drugs mentioned above are approved in the United States for the treatment of portal hypertension. Their use in patients with portal hypertension is therefore considered offlabel.

A shunt connecting the hypertensive portal system and low-pressure systemic veins reverses portal hypertension; this can be achieved percutaneously through the placement of a transjugular intrahepatic portosystemic shunt or surgically.

\section{LOCAL THERAPIES WITHOUT PORTAL PRESSURE- REDUCING EFFECTS}

Endoscopic procedures can be used to place elastic bands on variceal columns (variceal ligation) or to inject sclerosing agents (variceal sclerotherapy) or tissue adhesives (variceal obturation) into gastroesophageal varices. ${ }^{23}$ These techniques can achieve variceal obliteration (sometimes called "eradication"). However, gastroesophageal varices will eventually recur; therefore, close endoscopic surveillance and retreatment are necessary. Other shorter-term temporizing local measures include balloon tamponade and placement of expandable esophageal stents. ${ }^{24}$ 


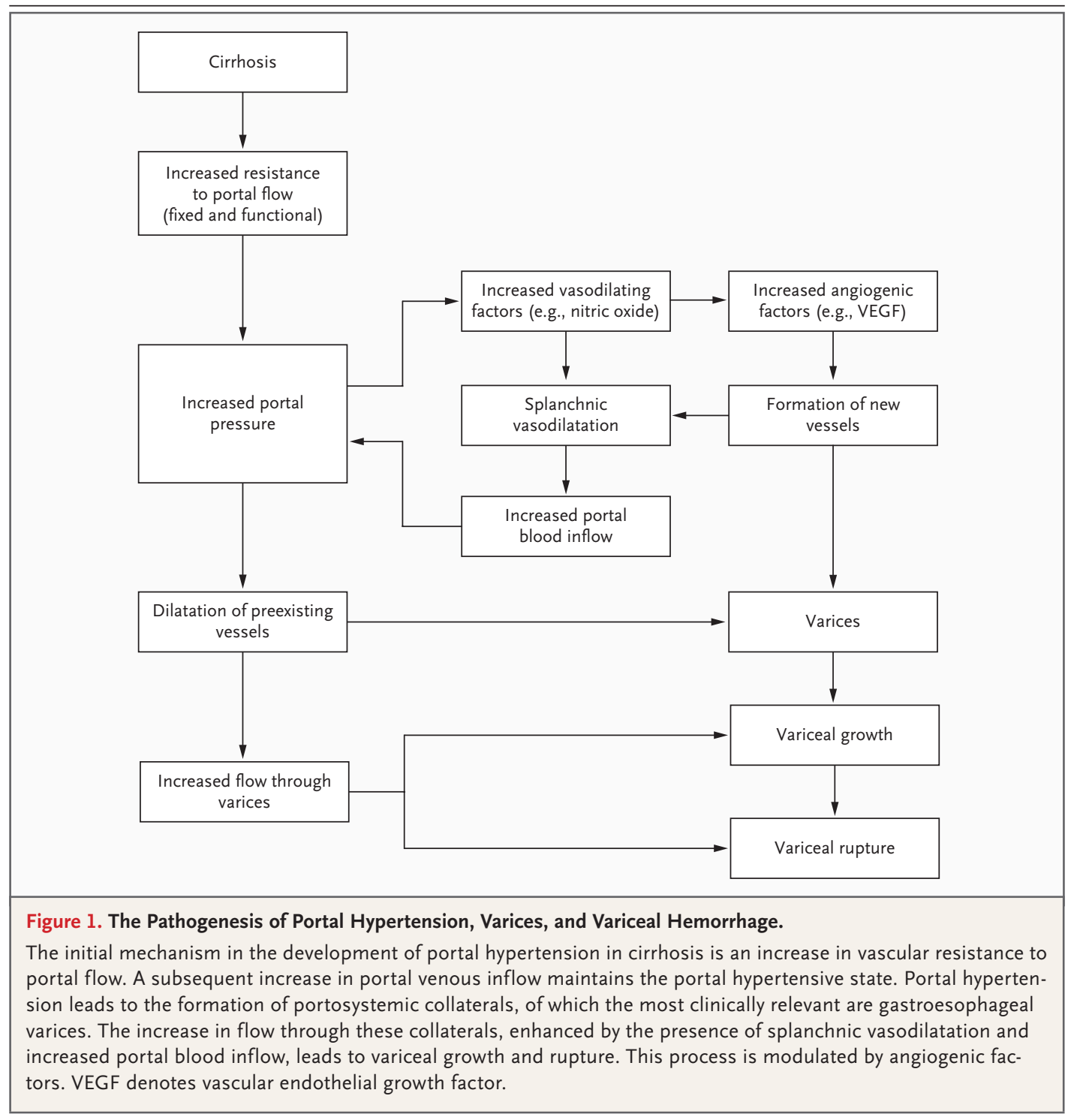

\section{RISK STRATIFICATION FOR PATIENTS WITH PORTAL HYPERTENSION}

One of the main issues confounding screening of and therapeutic studies involving patients with cirrhosis is a lack of proper risk stratification. At a minimum, patients should be stratified according to whether they have compensated or decompensated cirrhosis. ${ }^{25}$

In patients with compensated cirrhosis (i.e., those who do not have ascites, variceal hemorrhage, encephalopathy, or jaundice), risk stratification starts with an assessment for the presence of gastroesophageal varices. Patients with gastroesophageal varices have a higher rate of death and a greater risk of decompensation than those without gastroesophageal varices. ${ }^{26}$ The recommended method to determine the presence and size of gastroesophageal varices is esophagogastroduodenoscopy. ${ }^{1,2,27}$ Less invasive methods such as capsule endoscopy are being investigated and may be preferred by patients; however, their accuracy in evaluating the presence of varices, red wale marks, and variceal size is still suboptimal. ${ }^{27}$ Similarly, a ratio of platelet count (per cubic millimeter) to spleen size (the maximum bipolar di- 
ameter in millimeters by ultrasonography) above 909 has a high negative predictive value (i.e., the patient is unlikely to have varices). ${ }^{28}$ However, this ratio requires further validation. ${ }^{29}$

In patients without varices and in those with variceal hemorrhage, measurement of portal pressure with the use of the hepatic venous pressure gradient (HVPG) is the best method to stratify risk. Portal hypertension is present when the HVPG is greater than $5 \mathrm{~mm} \mathrm{Hg}$, but it is considered clinically significant when the HVPG is greater than $10 \mathrm{~mm} \mathrm{Hg}$, because in patients without varices, this pressure is the strongest predictor of the development of varices, ${ }^{5}$ clinical decompensation, ${ }^{30}$ and hepatocellular carcinoma. ${ }^{31}$ In patients with variceal hemorrhage, an HVPG of more than $20 \mathrm{~mm} \mathrm{Hg}$ (measured within 24 hours after admission) is the best predictor of a poor outcome. ${ }^{32}$ In contrast, a reduction in the HVPG to less than $12 \mathrm{~mm} \mathrm{Hg}$ or a reduction of more than $20 \%$ from the baseline value is associated with a decreased risk of variceal hemorrhage and improved survival. ${ }^{33,34}$

The HVPG is obtained by means of catheterization of a hepatic vein with a balloon catheter through a jugular or femoral vein. Although the procedure to obtain the HVPG is simple and safe (see the video, available with the full text of this article at NEJM.org), it is invasive and its use is not widespread in the United States. Standardization of the technique through the creation of multisociety guidelines, certification, and quality control is needed to help bring the HVPG into wider clinical use. $^{3}$

Measurement of liver stiffness, a technique not yet widely available in the United States, is a noninvasive method that correlates reasonably well with the HVPG, particularly at HVPG values below $10 \mathrm{~mm} \mathrm{Hg} .{ }^{35}$ Therefore, it appears to be useful in identifying the presence of clinically significant portal hypertension. Notably, the presence of varices (or collaterals on imaging studies) indicates that clinically significant portal hypertension is present.

The Child class or its laboratory components (the levels of bilirubin and albumin and the international normalized ratio) correlate roughly with clinically significant portal hypertension ${ }^{36}$ and can be used to stratify risk in both compensated and decompensated cirrhosis. ${ }^{26}$ In patients with variceal hemorrhage, Child class $\mathrm{C}$ has been associated with an HVPG of more than $20 \mathrm{~mm} \mathrm{Hg}$ and a poor outcome. ${ }^{11}$ The Model for End-Stage
Liver Disease score, which is used for organ allocation in liver transplantation, has been shown to predict the development of decompensation in patients without varices ${ }^{30}$ and to predict 6-week mortality after variceal hemorrhage. ${ }^{37}$

PREVENTION OF VARICES AND

A FIRST VARICEAL HEMORRHAGE

Patients without gastroesophageal varices or with gastroesophageal varices that have never bled are at relatively low risk for bleeding and death, and therefore, therapies for these patients should be the least invasive. In patients without varices, treatment with nonselective beta-blockers is not recommended because they do not prevent the development of varices and are associated with side effects. ${ }^{5}$

In patients with low-risk, small varices (without red wale marks and in the absence of severe liver disease), nonselective beta-blockers may delay variceal growth and thereby prevent variceal hemorrhage. ${ }^{38}$ These agents are considered optional, given the limited existing evidence, the low-risk setting, and the alternative of periodic screening for variceal growth.

In patients with small varices that are associated with a high risk of hemorrhage (varices with red wale marks or varices in a patient with Child class $\mathrm{B}$ or $\mathrm{C}$ disease), nonselective beta-blockers are recommended.

In patients with medium or large varices, either nonselective beta-blockers or endoscopic variceal ligation can be used, since a meta-analysis of high-quality, randomized, controlled trials has shown equivalent efficacy and no differences in survival. ${ }^{39}$ The advantages of nonselective betablockers are that their cost is low, expertise is not required for their use, and they may prevent other complications, such as bleeding from portal hypertensive gastropathy, ascites, and spontaneous bacterial peritonitis because they reduce portal pressure. ${ }^{33,40,41}$ The disadvantages of these agents include relatively common contraindications and side effects (fatigue and shortness of breath) that preclude treatment or require discontinuation in 15 to $20 \%$ of patients. The advantages of endoscopic variceal ligation are that it can be performed at the time of screening endoscopy and that its side effects are less frequent. However, specific expertise is necessary, and there is potential for lethal hemorrhage from postprocedure ulcers. ${ }^{17}$ Some centers perform endoscopic variceal liga- 


\begin{tabular}{|c|c|c|c|c|}
\hline Regimen & Dose & Goal & Duration & Follow-up \\
\hline Propranolol & $\begin{array}{l}\text { Starting dose of } 20 \mathrm{mg} \\
\quad \text { given orally twice a day }\end{array}$ & $\begin{array}{l}\text { Increase to maximally tolerated } \\
\text { dose or until heart rate is } \\
\text { approximately } 55 \text { beats } / \mathrm{min}\end{array}$ & Indefinite & $\begin{array}{l}\text { Ensure heart-rate goals met } \\
\text { at each clinic visit; no } \\
\text { need for follow-up } \\
\text { endoscopy }\end{array}$ \\
\hline Nadolol & $\begin{array}{l}\text { Starting dose of } 40 \mathrm{mg} \\
\text { given orally once a day }\end{array}$ & $\begin{array}{l}\text { Increase to maximally tolerated } \\
\text { dose or until heart rate is } \\
\text { approximately } 55 \text { beats } / \mathrm{min}\end{array}$ & Indefinite & $\begin{array}{l}\text { Ensure heart-rate goals met } \\
\text { at each clinic visit; no } \\
\text { need for follow-up } \\
\text { endoscopy }\end{array}$ \\
\hline $\begin{array}{l}\text { Endoscopic } \\
\quad \text { variceal ligation }\end{array}$ & Every 2-4 weeks & Obliterate varices & $\begin{array}{l}\text { Until variceal obliteration } \\
\text { achieved (usually } 2-4 \\
\text { sessions) }\end{array}$ & $\begin{array}{l}\text { Perform first surveillance } \\
\text { endoscopy } 1-3 \text { mo after } \\
\text { obliteration, then every } \\
6-12 \text { mo indefinitely }\end{array}$ \\
\hline
\end{tabular}

* Therapies that should not be used as prophylaxis include nitrates alone, endoscopic variceal sclerotherapy, shunt therapy (either transjugular intrahepatic portosystemic shunt or surgical shunt), nonselective beta-blockers plus endoscopic variceal ligation, and nonselective betablockers plus nitrates.

$\dagger$ Only one of the three regimens should be used.

tion in most patients, whereas other centers prefer to use nonselective beta-blockers initially, switching to endoscopic variceal ligation in patients with intolerance or contraindications to nonselective beta-blockers; the latter is a rational approach. The schedule, doses, goals, and followup of therapies for primary prophylaxis are shown in Table 2 (see Fig. 1 in the Supplementary Appendix, available with the full text of this article at NEJM.org).

Carvedilol at low doses ( 6.25 to $12.5 \mathrm{mg}$ per day) was compared with endoscopic variceal ligation in a recent randomized, controlled trial. ${ }^{42}$ Carvedilol was associated with lower rates of first variceal hemorrhage (10\% vs. $23 \%$ ) and had an acceptable side-effect profile, unlike endoscopic variceal ligation, for which compliance was low and the rate of first hemorrhage was at the upper end of the range of rates in previous studies. ${ }^{42}$ Whether carvedilol is more effective or better tolerated than nonselective beta-blockers remains to be determined.

TREATMENT OF ACUTE VARICEAL HEMORRHAGE

The rate of death from acute variceal hemorrhage has been decreasing over the past two decades, probably as a result of improved general management (with prophylactic antibiotics) and more effective therapies (endoscopic variceal ligation and vasoactive drugs). ${ }^{43}$ Although therapy is not currently targeted at specific risk groups, recent data suggest that in patients at high risk (Child class C or an HVPG of $>20 \mathrm{~mm} \mathrm{Hg}$ ), the approach should be more aggressive.

Patients who have Child class A or B disease or who have an HVPG of less than $20 \mathrm{~mm} \mathrm{Hg}$ have a low or intermediate risk and should receive standard therapy - specifically, the combination of a safe vasoconstrictor (terlipressin, somatostatin, or analogues such as octreotide or vapreotide, administered from the time of admission and maintained for 2 to 5 days) and endoscopic therapy (preferably endoscopic variceal ligation, performed at diagnostic endoscopy $<12$ hours after admission), ${ }^{10,44}$ together with short-term prophylactic antibiotics (either norfloxacin or ceftriaxone). ${ }^{45,46}$ The only vasoconstrictor currently available in the United States is octreotide. In other countries, the choice of vasoconstrictor depends on availability and cost. Antibiotic prophylaxis with ceftriaxone is recommended in patients with severe liver disease, particularly if they are receiving quinolone prophylaxis, whereas others can receive oral norfloxacin or intravenous ciprofloxacin (Table 3).

Placement of a transjugular intrahepatic portosystemic shunt is currently considered a salvage therapy for the 10 to $20 \%$ of patients in whom standard medical therapy fails (Fig. 2 in the Supplementary Appendix). However, two randomized, controlled trials have shown that early placement of such a shunt (within 24 to 48 hours after admission) was associated with significant improvement in survival among high-risk patients (i.e., patients with an HVPG $>20 \mathrm{~mm} \mathrm{Hg}^{48}$ or with Child class $\mathrm{C}$ disease with a score between 10 and 13 points $^{49}$ [Table 1]). Therefore, early place- 


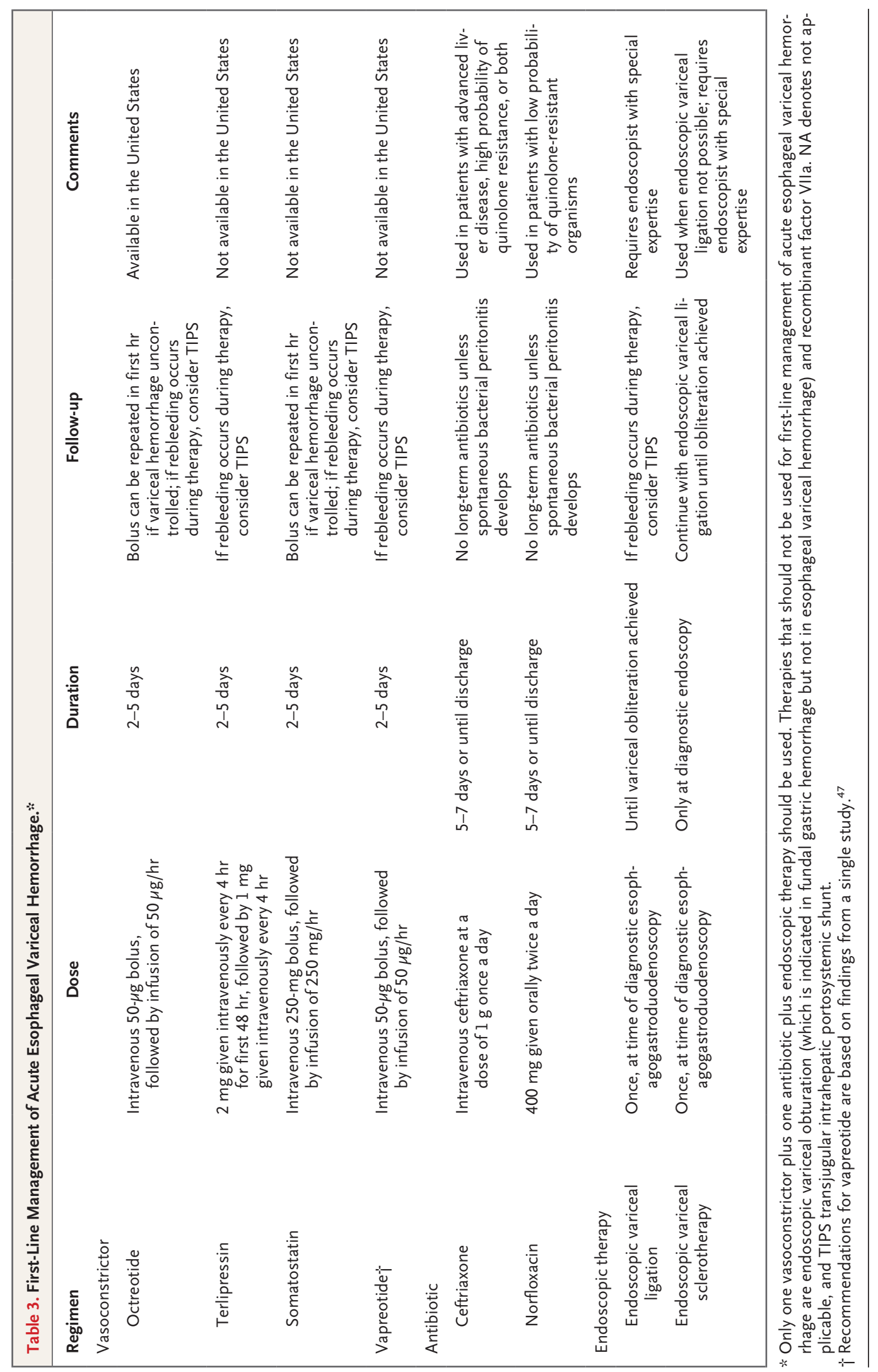


ment of a transjugular intrahepatic portosystemic shunt could be considered in these patients and, although this deserves further investigation, the decision to use this approach as salvage therapy in this high-risk population should be made sooner rather than later. In these patients, the use of recombinant factor VII has been found to be of little value. ${ }^{12}$

Gastric varices are present in $20 \%$ of patients with cirrhosis, either in isolation or in combination with esophageal varices. Bleeding from fundal varices is more severe and is associated with a higher rate of death than bleeding from gastroesophageal varices. ${ }^{50}$

Endoscopic variceal obturation with the use of tissue adhesives such as N-butyl-2-cyanoacrylate is more effective than endoscopic variceal ligation in controlling initial hemorrhage and preventing rebleeding from gastric varices. ${ }^{51,52} \mathrm{~A}$ transjugular intrahepatic portosystemic shunt is also effective in patients with bleeding fundal varices. In a recent randomized, controlled trial in which endoscopic variceal obturation was used to control acute hemorrhage in all patients (with a 93\% success rate), a transjugular intrahepatic portosystemic shunt was more effective than endoscopic variceal obturation in preventing recurrent hemorrhage..$^{53}$

Even though fundal varices were the source of bleeding in less than half the patients included in these studies and vasoactive drugs have not been investigated, data suggest that endoscopic variceal obturation is the best endoscopic technique to control acute hemorrhage and the transjugular intrahepatic portosystemic shunt is more effective than variceal obturation in preventing recurrent hemorrhage. Among tissue adhesives, $\mathrm{N}$-butyl-2-cyanoacrylate is not available in the United States, and although the off-label use of another adhesive, 2-octyl cyanoacrylate, has been reported, ${ }^{54}$ endoscopic variceal obturation requires careful attention to technique and is not free of serious complications. If an endoscopist with the requisite expertise is unavailable, placement of a transjugular intrahepatic portosystemic shunt should be considered first-line therapy when bleeding is not controlled by vasoactive drugs.

Currently, treatment recommendations apply to all patients with variceal hemorrhage. Patients with Child class A disease have a good response to current therapies, with a minimal risk of death (0 to $5 \%$ ). Whether pharmacologic therapy alone would suffice in these patients deserves further examination. Strategies are being investigated that may improve survival in patients with Child class $\mathrm{C}$ disease, but new strategies should be investigated for those at intermediate risk (Child class B).

\section{PREVENTION OF RECURRENT VARICEAL HEMORRHAGE}

Given the high recurrence rate, patients who survive an acute variceal hemorrhage should receive therapy to prevent recurrence before they are discharged from the hospital. Combination pharmacologic therapy (nonselective beta-blockers plus nitrates) or combination endoscopic variceal ligation plus drug therapy are warranted because of the high risk of recurrence, even though the side effects will be greater than those with singleagent therapy (recommended for primary prophylaxis).

These two strategies were compared in a randomized, controlled trial that showed a significantly lower rate of variceal rebleeding with a combination of endoscopic variceal ligation and drug therapy (nonselective beta-blockers plus nitrates) than with drug therapy alone. However, the rate of hemorrhage from all sources was not significantly different because of bleeding from esophageal ulcers induced by endoscopic variceal ligation. ${ }^{55}$

A meta-analysis showed that rates of rebleeding (from all sources and from varices) are lower with a combination of endoscopic therapy plus drug therapy than with either therapy alone, but without differences in survival. ${ }^{56}$ Therefore, current guidelines recommend the combined use of endoscopic variceal ligation and nonselective betablockers for the prevention of recurrent variceal hemorrhage, even in patients who have had a recurrent hemorrhage despite treatment with nonselective beta-blockers or endoscopic variceal ligation for primary prophylaxis. In patients who are not candidates for endoscopic variceal ligation, the strategy would be to maximize portal-pressure reduction by combining nonselective beta-blockers plus nitrates.

Patients who have rebleeding despite combined treatment with endoscopic variceal ligation and drugs at the recommended doses and schedule (Table 4) should undergo percutaneous placement of a transjugular intrahepatic portosystemic shunt 


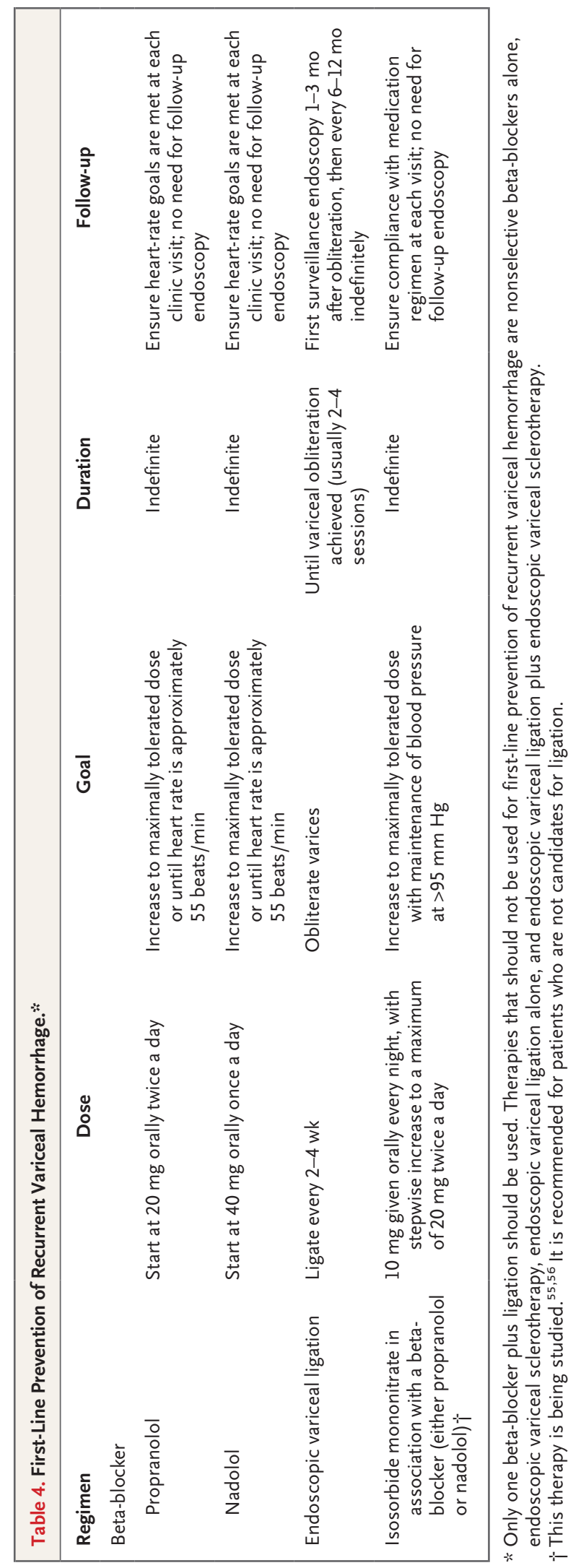

or surgical creation of a shunt; the two shunts are equally effective (Fig. 3 in the Supplementary Appendix). ${ }^{57}$ The need for frequent revision of a transjugular intrahepatic portosystemic shunt, reported in a randomized, controlled trial, ${ }^{57}$ appears to have been overcome with the current use of coated stents, which have a significantly lower occlusion rate. ${ }^{58}$ The choice between a transjugular intrahepatic portosystemic shunt and surgery will therefore depend on local expertise and the patient's preference.

The rate of recurrent variceal hemorrhage is lowest (approximately 10\%) among patients in whom the HVPG decreases to less than $12 \mathrm{~mm} \mathrm{Hg}$ or is reduced by more than $20 \%$ from the baseline value. ${ }^{9,34}$ Perhaps the most rational approach to the prevention of recurrent hemorrhage would be to choose therapies on the basis of the HVPG response; however, the issue will remain unresolved until randomized, controlled trials show that HVPG-guided therapy is superior to the current empirical treatment.

Other than the HVPG response, therapeutic approaches in patients who have recovered from variceal hemorrhage are not targeted at specific risk groups. Given that the severity of liver disease has been consistently shown to be a good predictor of recurrent hemorrhage and death, the Child classification could also be a good way to stratify patients according to risk. Although patients with Child class A disease may require only pharmacologic therapy, more aggressive combination therapies would be required in patients with a high risk (i.e., patients with Child class B or C disease and patients on the transplantation list).

\section{SPECIAL SITUATIONS FOR WHICH} THERE IS LIMITED OR NO EVIDENCE

\section{PORTAL HYPERTENSIVE GASTROPATHY}

Portal hypertensive gastropathy is a portal hypertension-related gastrointestinal mucosal lesion characterized by ectatic gastric mucosal vessels mostly in the fundus and body of the stomach. The presence of gastroesophageal varices and the Child class are predictive of portal hypertensive gastropathy, whereas its development or its progression from mild to severe correlates only with the Child class. ${ }^{59}$ Although the prevalence of portal hypertensive gastropathy is higher among patients who have undergone endoscopic therapy (sclerotherapy or endoscopic variceal ligation) than 
among those who have not, ${ }^{60,61}$ the clinical course is the same. The most common presentation, occurring mainly in patients with severe portal hypertensive gastropathy, is chronic, slow hemorrhage resulting in anemia. The initial management consists of iron supplementation and use of nonselective beta-blockers; this therapy has been shown in a randomized, controlled trial to be effective in preventing recurrent hemorrhage. ${ }^{40}$ If hemorrhage continues and the patient requires frequent transfusions, shunt therapy (either a transjugular intrahepatic portosystemic shunt or shunt surgery) should be considered.

\section{ASSOCIATED PORTAL-VEIN THROMBOSIS}

The development of portal-vein thrombosis is an important event in the natural history of advanced cirrhosis. ${ }^{62}$ It is associated with worsening liver function, ascites, and variceal hemorrhage. The incidence of portal-vein thrombosis is approximately $16 \%$ per year in patients with advanced liver disease. Treatment for portal-vein thrombosis in these patients (e.g., with anticoagulation, thrombolysis, or placement of a transjugular intrahepatic portosystemic shunt) is currently determined on a caseby-case basis. ${ }^{63}$

Supported by grants from the Fundación Banco Bilbao Vizcaya Argentaria, Instituto de Salud Carlos III (PI 09/01261, Centro de Investigación Biomédica en Red de Enfermedades Hepáticas y Digestivas), and Yale Liver Center (NIH P30 DK34989).

Dr. Garcia-Tsao reports receiving consulting fees from Debiovision and Salix; and Dr. Bosch, receiving consulting fees from Astellas, Axcan-NicOx, Chiasma, and Dominion-Pharmakine, lecture fees from Ferring and Gore, and grant support from Astellas and Axcan-NicOx and holding patents, from which he receives no income, for catheters used in measurement of the hepatic venous pressure gradient and in antiangiogenic treatment. No other potential conflict of interest relevant to this article was reported.

\section{REFERENCES}

1. Garcia-Tsao G, Sanyal AJ, Grace ND, Carey W, Practice Guidelines Committee of the American Association for the Study of Liver Diseases, Practice Parameters Committee of the American College of Gastroenterology. Prevention and management of gastroesophageal varices and variceal hemorrhage in cirrhosis. Hepatology 2007; 46:922-38. [Erratum, Hepatology 2007;46: 2052.]

2. de Franchis R. Evolving consensus in portal hypertension: report of the Baveno IV Consensus Workshop on methodology of diagnosis and therapy in portal hypertension. J Hepatol 2005;43:167-76. [Erratum, J Hepatol 2005;43:547.]

3. Garcia-Tsao G, Bosch J, Groszmann RJ. Portal hypertension and variceal bleeding - unresolved issues: summary of an American Association for the Study of Liver Diseases and European Association for the Study of the Liver single-topic conference. Hepatology 2008;47:1764-72.

4. Kovalak M, Lake J, Mattek N, Eisen G, Lieberman D, Zaman A. Endoscopic screening for varices in cirrhotic patients: data from a national endoscopic database. Gastrointest Endosc 2007;65:82-8.

5. Groszmann RJ, Garcia-Tsao G, Bosch $\mathrm{J}$, et al. Beta-blockers to prevent gastroesophageal varices in patients with cir rhosis. N Engl J Med 2005;353:2254-61.

6. Merli M, Nicolini G, Angeloni S, et al. Incidence and natural history of small esophageal varices in cirrhotic patients. J Hepatol 2003;38:266-72.

7. D'Amico G, Pagliaro L, Bosch J. Pharmacological treatment of portal hyperten sion: an evidence-based approach. Semin Liver Dis 1999;19:475-505.

8. The North Italian Endoscopic Club for the Study and Treatment of Esophageal
Varices. Prediction of the first variceal hemorrhage in patients with cirrhosis of the liver and esophageal varices: a prospective multicenter study. N Engl J Med 1988;319:983-9.

9. Bosch J, García-Pagán JC. Prevention of variceal rebleeding. Lancet 2003;361:952-4. 10. Villanueva C, Piqueras M, Aracil C, et al. A randomized controlled trial comparing ligation and sclerotherapy as emergency endoscopic treatment added to somatostatin in acute variceal bleeding. J Hepatol 2006;45:560-7.

11. Abraldes JG, Villanueva C, Bañares R, et al. Hepatic venous pressure gradient and prognosis in patients with acute variceal bleeding treated with pharmacologic and endoscopic therapy. J Hepatol 2008; 48:229-36.

12. Bosch J, Thabut D, Albillos A, et al. Recombinant factor VIIa for variceal bleeding in patients with advanced cirrhosis: a randomized, controlled trial. Hepatology 2008;47:1604-14.

13. Iwakiri Y, Groszmann RJ. Vascular endothelial dysfunction in cirrhosis. J Hepatol 2007;46:927-34.

14. Fernandez M, Mejias M, Garcia-Pras E, Mendez R, Garcia-Pagan JC, Bosch J. Reversal of portal hypertension and hyperdynamic splanchnic circulation by combined vascular endothelial growth factor and platelet-derived growth factor blockade in rats. Hepatology 2007;46:1208-17. 15. Mejias M, Garcia-Pras E, Tiani C, Miquel R, Bosch J, Fernandez M. Beneficial effects of sorafenib on splanchnic, intrahepatic, and portocollateral circulations in portal hypertensive and cirrhotic rats. Hepatology 2009;49:1245-56.

16. Iwakiri Y, Groszmann RJ. The hyperdynamic circulation of chronic liver dis- eases: from the patient to the molecule. Hepatology 2006;43:Suppl 1:S121-S131.

17. Bosch J, Berzigotti A, Garcia-Pagan JC, Abraldes JG. The management of portal hypertension: rational basis, available treatments and future options. J Hepatol 2008;48:Suppl 1:S68-S92.

18. Schepke M, Werner E, Biecker E, et al. Hemodynamic effects of the angiotensin II receptor antagonist irbesartan in patients with cirrhosis and portal hypertension. Gastroenterology 2001;121:389-95. 19. González-Abraldes J, Albillos A, Bañares R, et al. Randomized comparison of long-term losartan versus propranolol in lowering portal pressure in cirrhosis. Gastroenterology 2001;121:382-8.

20. Abraldes JG, Rodríguez-Vilarrupla A, Graupera M, et al. Simvastatin treatment improves liver sinusoidal endothelial dysfunction in $\mathrm{CCl} 4$ cirrhotic rats. J Hepatol 2007;46:1040-6.

21. Abraldes JG, Albillos A, Bañares R, et al. Simvastatin lowers portal pressure in patients with cirrhosis and portal hypertension: a randomized controlled trial. Gastroenterology 2009;136:1651-8.

22. Bañares $R$, Moitinho $E$, Matilla $A$, et al. Randomized comparison of long-term carvedilol and propranolol administration in the treatment of portal hypertension in cirrhosis. Hepatology 2002;36:1367-73.

23. Laine L, Cook D. Endoscopic ligation compared with sclerotherapy for treatment of esophageal variceal bleeding: a metaanalysis. Ann Intern Med 1995;123:280-7. 24. Hubmann R, Bodlaj G, Czompo M, et al. The use of self-expanding metal stents to treat acute esophageal variceal bleeding. Endoscopy 2006;38:896-901.

25. Garcia-Tsao G, Friedman S, Iredale J, Pinzani M. Now there are many (stages) 
where there once was one: in search of a pathophysiological classification of cirrhosis. Hepatology 2009 November 30 (Epub ahead of print).

26. D’Amico G, Garcia-Tsao G, Pagliaro L. Natural history and prognostic indicators of survival in cirrhosis: a systematic review of 118 studies. J Hepatol 2006;44: 217-31.

27. de Franchis R, Eisen GM, Laine L, et al. Esophageal capsule endoscopy for screening and surveillance of esophageal varices in patients with portal hypertension. Hepatology 2008;47:1595-603.

28. Giannini E, Botta F, Borro P, et al. Platelet count/spleen diameter ratio: proposal and validation of a non-invasive parameter to predict the presence of oesophageal varices in patients with liver cirrhosis. Gut 2003;52:1200-5.

29. D’Amico G, Morabito A. Noninvasive markers of esophageal varices: another round, not the last. Hepatology 2004;39: 30-4.

30. Ripoll C, Groszmann R, Garcia-Tsao $\mathrm{G}$, et al. Hepatic venous pressure gradient predicts clinical decompensation in patients with compensated cirrhosis. Gastroenterology 2007;133:481-8.

31. Ripoll C, Groszmann RJ, Garcia-Tsao $\mathrm{G}$, et al. Hepatic venous pressure gradient predicts development of hepatocellular carcinoma independently of severity of cirrhosis. J Hepatol 2009;50:923-8.

32. Moitinho E, Escorsell A, Bandi JC, et al. Prognostic value of early measurements of portal pressure in acute variceal bleeding. Gastroenterology 1999;117:626-31.

33. Abraldes JG, Tarantino I, Turnes J, Garcia-Pagan JC, Rodés J, Bosch J. Hemodynamic response to pharmacological treatment of portal hypertension and longterm prognosis of cirrhosis. Hepatology 2003;37:902-8.

34. D’Amico G, Garcia-Pagan JC, Luca A, Bosch J. Hepatic vein pressure gradient reduction and prevention of variceal bleeding in cirrhosis: a systematic review. Gastroenterology 2006;131:1611-24.

35. Vizzutti F, Arena U, Romanelli RG, et al. Liver stiffness measurement predicts severe portal hypertension in patients with HCV-related cirrhosis. Hepatology 2007;45: 1290-7.

36. Berzigotti A, Gilabert R, Abraldes JG, et al. Noninvasive prediction of clinically significant portal hypertension and esophageal varices in patients with compensated liver cirrhosis. Am J Gastroenterol 2008; 103:1159-67. [Erratum, Am J Gastroenterol 2008;103:2167.]

37. Bambha K, Kim WR, Pedersen RA, Bida JP, Kremers WK, Kamath PS. Predictors of early re-bleeding and mortality after acute variceal hemorrhage in patients with cirrhosis. Gut 2008;57:814-20.
38. Merkel C, Marin R, Angeli P, et al. A placebo-controlled clinical trial of nadolol in the prophylaxis of growth of small esophageal varices in cirrhosis. Gastroenterology 2004;127:476-84.

39. Gluud LL, Klingenberg S, Nikolova D, Gluud C. Banding ligation versus betablockers as primary prophylaxis in esophageal varices: systematic review of randomized trials. Am J Gastroenterol 2007, 102:2842-8.

40. Pérez-Ayuso RM, Piqué JP, Bosch J, et al. Propranolol in prevention of recurrent bleeding from severe portal hypertensive gastropathy in cirrhosis. Lancet 1991;337: 1431-4.

41. Casado M, Bosch J, García-Pagán JC et al. Clinical events after transjugular intrahepatic portosystemic shunt: correlation with hemodynamic findings. Gastroenterology 1998;114:1296-303.

42. Tripathi D, Ferguson JW, Kochar N, et al. Randomized controlled trial of carvedilol versus variceal band ligation for the prevention of the first variceal bleed. Hepatology 2009;50:825-33.

43. Carbonell N, Pauwels A, Serfaty L, Fourdan O, Lévy VG, Poupon R. Improved survival after variceal bleeding in patients with cirrhosis over the past two decades. Hepatology 2004;40:652-9.

44. Bañares R, Albillos $\mathrm{A}$, Rincón $\mathrm{D}$, et al Endoscopic treatment versus endoscopic plus pharmacologic treatment for acute variceal bleeding: a meta-analysis. Hepatology 2002;35:609-15.

45. Bernard B, Grangé JD, Khac EN, Amiot X, Opolon P, Poynard T. Antibiotic prophylaxis for the prevention of bacterial infections in cirrhotic patients with gastrointestinal bleeding: a meta-analysis Hepatology 1999;29:1655-61.

46. Fernández J, Ruiz del Arbol L, Gómez $\mathrm{C}$, et al. Norfloxacin vs ceftriaxone in the prophylaxis of infections in patients with advanced cirrhosis and hemorrhage. Gastroenterology 2006;131:1049-56.

47. Cales P, Masliah C, Bernard B, et al Early administration of vapreotide for variceal bleeding in patients with cirrhosis. N Engl J Med 2001;344:23-8.

48. Monescillo A, Martínez-Lagares F, Ruiz-del-Arbol L, et al. Influence of portal hypertension and its early decompression by TIPS placement on the outcome of variceal bleeding. Hepatology 2004;40:793801.

49. Garcia-Pagán JC, Caca K, Bureau C, et al. An early decision for PTFE-TIPS improves survival in high risk cirrhotic patients admitted with an acute variceal bleeding: a multicenter RCT. Hepatology 2008;48:Suppl:373A-374A. abstract.

50. Ryan BM, Stockbrugger RW, Ryan JM. A pathophysiologic, gastroenterologic, and radiologic approach to the management of gastric varices. Gastroenterology 2004; 126:1175-89.

51. Lo GH, Lai KH, Cheng JS, Chen MH, Chiang HT. A prospective, randomized trial of butyl cyanoacrylate injection versus band ligation in the management of bleeding gastric varices. Hepatology 2001;33:1060-4. 52. Tan PC, Hou MC, Lin HC, et al. A randomized trial of endoscopic treatment of acute gastric variceal hemorrhage: N-butyl2-cyanoacrylate injection versus band ligation. Hepatology 2006;43:690-7. [Erratum, Hepatology 2006;43:1410.]

53. Lo GH, Liang HL, Chen WC, et al. A prospective, randomized controlled trial of transjugular intrahepatic portosystemic shunt versus cyanoacrylate injection in the prevention of gastric variceal rebleeding. Endoscopy 2007;39:679-85.

54. Rengstorff DS, Binmoeller KF. A pilot study of 2-octyl cyanoacrylate injection for treatment of gastric fundal varices in humans. Gastrointest Endosc 2004;59:553-8. 55. García-Pagán JC, Villanueva C, Albillos A, et al. Nadolol plus isosorbide mononitrate alone or associated with band ligation in the prevention of recurrent bleeding: a multicentre randomised controlled trial. Gut 2009;58:1144-50.

56. Gonzalez R, Zamora J, Gomez-Camarero J, Molinero LM, Bañares R, Albillos A. Combination endoscopic and drug therapy to prevent variceal rebleeding in cirrhosis. Ann Intern Med 2008;149:109-22. 57. Henderson JM, Boyer TD, Kutner MH, et al. Distal splenorenal shunt versus transjugular intrahepatic portal systemic shunt for variceal bleeding: a randomized trial. Gastroenterology 2006;130:1643-51.

58. Bureau C, Garcia-Pagan JC, Otal P, et al. Improved clinical outcome using polytetrafluoroethylene-coated stents for TIPS: results of a randomized study. Gastroenterology 2004;126:469-75.

59. Ripoll C, Garcia-Tsao G. Treatment of gastropathy and gastric antral vascular ectasia in patients with portal hypertension. Curr Treat Options Gastroenterol 2007; 10:483-94.

60. Primignani M, Carpinelli L, Preatoni P, et al. Natural history of portal hypertensive gastropathy in patients with liver cirrhosis. Gastroenterology 2000;119:1817.

61. Sarin SK, Shahi H, Jain M, Jain AK, Issar SK, Murthy NS. The natural history of portal hypertensive gastropathy: influence of variceal eradication. Am J Gastroenterol 2000;95:2888-93.

62. Garcia-Pagan JC, Valla DC. Portal vein thrombosis: a predictable milestone in cirrhosis? J Hepatol 2009;51:632-4.

63. DeLeve LD, Valla DC, Garcia-Tsao G. Vascular disorders of the liver. Hepatology 2009;49:1729-64.

Copyright (C) 2010 Massachusetts Medical Society. 